\title{
Balanced Key Performance Indicators in Product Development
}

\author{
U. Dombrowski, K. Schmidtchen, and D. Ebentreich
}

\begin{abstract}
In today's business environment many enterprises react to changing conditions by the implementation of lean production systems. Lean offers an approach to eliminate waste and increase customer value in all processes. In the past, the focus of lean has been on the production and is now enhanced to other processes in the enterprise, e.g. product development or sales \& services. In particular research approaches, so called lean development, has been introduced to improve efficiency, effectiveness and the skills of staff and organization. Enterprises like Toyota, who work with lean principles in development, can develop products in significant shorter time-to-markets with higher quality and lower costs. Enterprises that applied lean to product development process are facing the challenge of defining key performance indicators to ensure the sustainability of the continuous improvement process. Therefore, the article gives an advice what requirements the performance indicators have to meet. Based on an analysis of $\mathbf{1 1}$ performance indicator systems the article shows that yet not all targets are covered by performance indicators. Thus the article shows an approach to develop an enterprise specific KPI-Set.
\end{abstract}

Index Terms-Key performance indicator, lean product development, product development, targets of product development.

\section{INTRODUCTION}

In the past, many manufacturing enterprises implemented lean production systems to reduce waste in the production processes and to increase the customer value. Focus for these optimization measures were the production, assembly, logistics, maintenance, and quality management. [1]

Due to shorter product life cycles and a stronger competition in many industries, the product development gains importance. Enterprises like Toyota, which work according to lean thinking in product development, have significantly shorter time-to-markets in addition to lower development costs. [2] Lean development systems are therefore a current trend and are in the focus of scientific research. Several approaches exist to implement the lean thinking in product development. [3] Main goal is to achieve a value-oriented, resource-efficient, and fast product innovation process. Key elements of a lean product development system are e.g. simultaneous engineering, supplier integration, set-based engineering or process standardization. [4]

After an enterprise has implemented a lean development system, it is important to establish it sustainably. The continuous improvement process ensures the lasting usage of the lean development system. An important prerequisite of

Manuscript received November 5, 2012; revised January 20, 2013.

The authors are with the Institute for Advanced Industrial Management, Braunschweig 38106 Germany (e-mail: k.schmidtchen@tu-bs.de). the continuous improvement process is the fixation of enterprise targets. By describing a future state, which should be attained, targets are a guideline to help employees to adjust their work [5]. They can differ in detail and occur on different hierarchy levels of the enterprise: for example, formal targets can describe the expected economic success of the entire enterprise or derived sub targets can be set for certain corporate divisions. [6] Targets should be expressed unambiguously, measurable and appointed. They should be achievable with the existing resources in a set time frame. [5]

To control the achievement of the targets enterprises use key performance indicators (KPI). The use of KPI enables the operationalisation of targets. KPI also correspond to the requirement of that targets and their degree of attainment need to be measurable. Besides an informational function KPI in an enterprise fulfill a coordinating function as well. KPI can be understood as information that "is able to express facts and circumstances briefly and relevant in a single indicator". [7]

In production, the use of KPI to attain targets is widespread. However, in product development a systematic measurement of KPI is not consistently implemented. Enterprises mostly suffer from a lack of suitable KPIs, which enable the operationalisation of targets. Thus, the requirements which an enterprise have to consider by the developing of an enterprise specific are shown. Furthermore, the article shows an approach for a suitable KPI-Set in product development.

\section{Challenges of Product DeVelopment}

The comparison of the differences between production and product development points out the challenges enterprises have to face when recording KPI.

In product development, the focus lies on the flow of information instead of material flow. In production, information and of material flow in opposite directions and the material flow is regarded predominantly. [2] In contrast, it is the information flow which is being considered primarily in product development. The information flow in product development is less transparent and therefore the identification and measurement are more difficult. [8] It is assumed that only 10 to 30 percent of all activities in product development are value-adding. The same amount of activities is non value-adding but necessary. Consequently, the amount of non-value creating activities (waste) is approximately 60 percent. [9]

Processes in product development are mainly not physical but cognitive. In production, the focus lies on physical processes such as manufacturing, assembly or logistics. [2] On the other hand cognitive processes include tasks, which 
concentrate on creative ways of finding solutions. Due to the different types of processes, methods cannot be applied exactly the same way. Through application of visual management or standardization, it is possible to identify waste in production. However, in product development, process transparency is often not existent and the identification of waste is difficult. Furthermore, standardization causes an unconsciously limiting the solution space. Longer time-to-market and higher costs are the result. [10]

Product development demands individual solutions instead of high rates of repetition. Tasks in production tend to be repetitive [8], [11] On the other hand, in product development, tasks are more often unique and the result of the task, e.g. product planning, is not foreseeable. Hence, a comparison of different development projects is only possible to a limited extent. Nevertheless, there are some activities in product development as well, which have a high rate of repetition, e.g. prototype testing.

Process times in product development are usually longer than in production. In production, process times of seconds and minutes are common, whereas in product development process times of weeks and months can be observed depending on the actual level of innovation [2], [11] Furthermore, the temporal measures in product development are often not well defined and are highly variable. This has a significant influence on the mapping process and also the continuous improvement process. [2]

\section{RUles FOR CREATING PERFORMANCE INDICATORS}

For the design of a performance measurement system, indicators should be selected according to specific criteria first. According to [12]-[15], these criteria are summarized in seven rules. These seven rules are described below in more detail:

\section{A. Relevance for the Enterprise Targets}

Nowadays the possibilities of compiling data and the use of information technology make it easier to gather a variety of indicators. However, not all indicators are suitable to support the targets of the enterprise. Therefore, it is necessary to create key indicator according to the target system of the enterprise. Thereto the target system needs to be analyzed and appropriate key indicators need to be selected. With appropriate key indicators, the employees are directed to support the targets [12] and [13].

\section{B. Quality of Data}

The quality of the basic data is critical to the effectiveness of a key indicator. The quality of an indicator is based in the validity and timeliness of data.

The validity of a key indicator is based on the recipient. Employees should be able to influence the indicator by their performance directly. Moreover, they must recognize their contribution by the indicators. Hence, the employee gets a better understanding for the indicator, which supports the validity. Enterprise-wide key indicators such as the total processing time cannot be traced back to the own work processes by the employee. The processing time of the own work processes, however, can be influenced comprehensible by the employee.

The timeliness of the key indicators depends on the circumstances. Fast feedback gives the employee a detailed profile of the performance and document the change over time. Otherwise a high frequency requires more effort for capturing the data. So the frequency is limited by the technical condition and the capacity of the employees [12].

\section{Compatibility to the Hierarchy}

Similar to targets, key indicators have to be adapted to the hierarchy. Some indicators could be used on all levels of the hierarchy, whereas other indicators must be derived from enterprise indicators. The key indicator annual net income or loss compared to the prior year, for example, should be represented on the staff level by the reject costs per employee. An indicator, which could be used on every hierarchy level, is turnover per employee. At the corporate level, the results of the different business units of the enterprise give an overall key indicator [14], [15].

\section{Variability}

Due to the dynamic business environment, enterprises are forced to react quickly to changes. The reaction of the enterprise is achieved by the change in the target weight. In line with the targets the key indicators must be adapted to the change, too. Particularly in target conflicts it is important to make clear which key indicator receives a greater weight [14], [15].

\section{E. Periodicity}

The periodicity of an indicator depends on the intended effect. A performance indicator for the future state is derived from the enterprise targets and has a long-term validity. The current state can be measured in shorter cycles to ensure the achievement of the targets. The period length also depends on the respective level. At the corporate level, longer periods are considered for an easier handling with summarized amount of information. In contrast, at the operational level shorter periods are used in order to receive a faster feedback. The feedback for the current state should not be longer than one month. The closer the recordings are to the value creation process, the more often, feedback should be given through the key indicator. [12]

\section{F. Visualization}

The visualization of the key indicators is important, so that the recipients will be reached. In addition to the key indicators for the current state the key indicators for the future state can be used for the alignment of the target achievement. Graphically edited key indicators help in understanding and perception. Additionally, an extension of the key indicators to action plans for the documentation of progress is possible. The visualization should be as close as possible to the workplace of employees to communicate the importance [12], [15].

\section{G. Effort}

The use of key indicators is involved with effort. In the generation, collection, processing, feedback and representation different tasks must be performed, which can be partly taken over by computer systems. The elicitation of the key indicator should always be evaluated by a 
cost-benefit analysis [12].

\section{TARgets of PRoduct DEVElopMent}

To analyze existing KPIs in product development it is necessary to identify the targets of product development. Therefore, the targets of product development could be based on the corporate targets of the enterprise. The identified targets could be summarized to three different target groups [16], [17].

Product development has two main target groups. First, for an enterprise it is necessary to design the right products to create a high market demand. This target group is called effectiveness. Furthermore, the products have to be developed efficiently. This means to design the product with the right process. To achieve these both target groups the required capabilities must be existent in the enterprise. Capabilities describe the third target group in product development. [16], [18] With the identified targets, derived from the three target groups effectiveness, efficiency, and capabilities it is possible to review existing KPI-Sets, to identify already existing KPIs in product development. Therefore, the KPI-Sets have to be analyzed in order to their fulfilment of the identified targets.

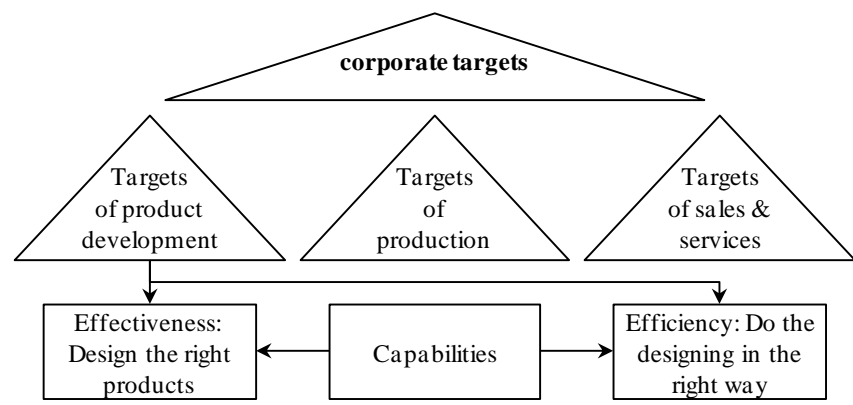

Fig. 1. Target groups of product development [16], [23]

In the following, the identified targets for the three target groups are described. Furthermore the results of the analysis of existing KPI-Sets are shown.

\section{A. Effectiveness}

First, it is crucial to identify the right ideas and transfer them as input into the process of development. The goal is to convert the market- and customer-needs into innovations. This target group is clustered under the term effectiveness ("Do the right things). In table I the target group effectiveness is shown. Furthermore, the table shows the analysis of existing KPI-Sets in order to their fulfillment of the identified targets [2], [16].

1) Due to the need for economic efficiency during the product lifecycle enterprises strive to achieve economic, efficient processes for the enterprise in the following product lifecycle phases like manufacturing and recycling. [18] A high number of KPIs for measuring the efficiency during the product life already exists. Many authors agree that the compliance to target costs, the return on investment (ROI) and the quota of standard parts are adequate indicators [19]-[21].
TABLE I: ANALYSIS OF CORPORATE TARGET EFFECTIVENESS

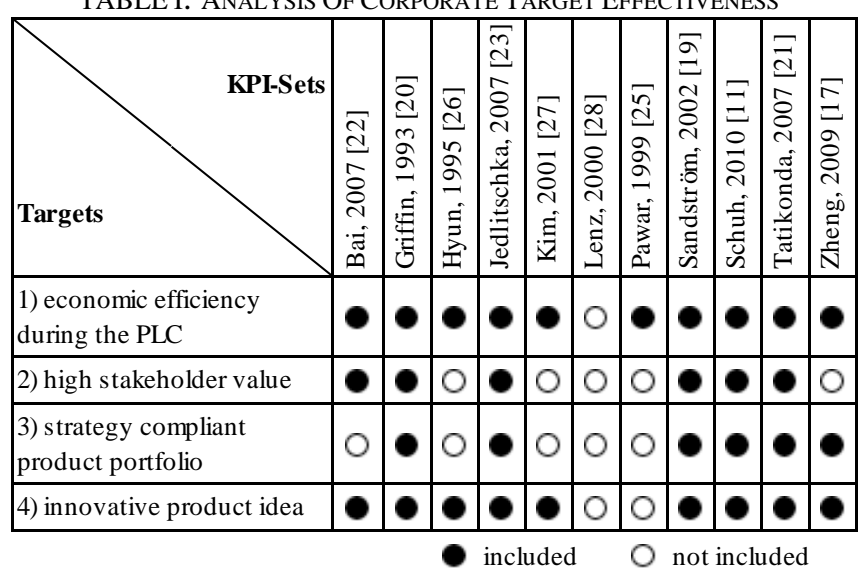

2) High stakeholder value describes the requirement that development increases the value for all stakeholders. [16] The literature shows a few indicators how to measure the stakeholder value of a product. The majority of the authors mention customer satisfaction, but often it remains unclear how to measure it [22], [23].

3) The strategy compliant product portfolio means the degree of congruency of the specific project with the superordinate vision, mission, and the long term strategy of the enterprise. [2] A very few number of KPIs are known to measure the compliance of the product portfolio with the enterprise strategy. Furthermore, the KPIs are not solely influenced by product development but also by other departments like marketing and production [19]-[21].

4) Innovative product idea refers to the degree of novelty of the product. Development projects without any innovation may just be positioned in the market by cost leadership. [17], [19] The KPIs concerning the innovation vary widely. Some KPIs e.g. degree of novelty are very subjective and may not be quantified in practice [17], [18].

\section{B. Efficiency}

In case the right ideas are picked and converted into projects, it is important to turn the input into great products and processes in the shortest time possible with a high quality and with minimal resources. Thus, the second main target group is efficiency ("Do things right") [16], [18].

TABLE II: ANALYSIS OF CORPORATE TARGET EFFICIENY

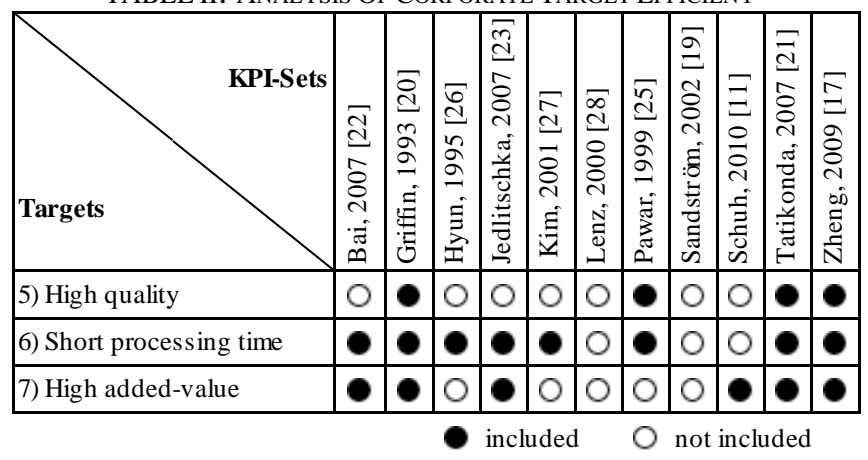

1) High quality refers to the accuracy of the result and the feasibility of the requirements of the task. [24] If the results are not satisfactory, project gets cancelled, or 
unplanned changes of the subsequent processes will need to be initiated. [2] A high variety of KPIs concerning the measurement of quality exists [17], [25].

2) Short processing time includes creating a short and predictable process of product development without any delays. Like its equivalent in production, the lead time is calculated by the sum of all preparation, handling, and idle times during the project. [2] For a clear determination and comparison, the start and end points have to be defined. In literature, a high accordance concerning the definition of KPIs for measuring the processing time exists [16], [22], [20], and [26].

3) High added-value comprises all efforts to complete the process of development with minimal expenses, e.g. costs of labor and material while at the same time achieving a high added-value. [2], [18] A high accordance concerning the definition of KPIs for measuring the added-value exists [11], [17], [20], and[21].

\section{Capabilities}

To make effective and efficient development possible, employees as well as the organization and the suppliers must be skilled properly. [16] Motivation, qualification, and the permission to decide on their own in clearly defined parameters are necessary for a high productivity in development. Thus, capabilities as the enabler for the two main target groups have to be regarded in a holistic KPI-Set. [16]

TABLE III: ANALYSIS OF CORPORATE TARGET CAPABILITIES

\begin{tabular}{|c|c|c|c|c|c|c|c|c|c|c|c|}
\hline KPI-Sets & 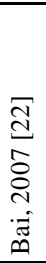 & 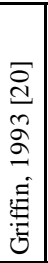 & 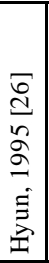 & 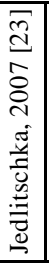 & 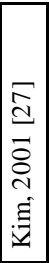 & 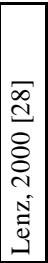 & 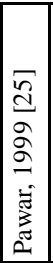 & 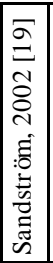 & 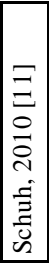 & 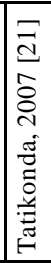 & 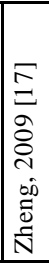 \\
\hline 8) Skilled employees & O & 0 & 0 & 0 & O & O & 0 & 0 & 0 & 0 & 0 \\
\hline 9) Skilled organization & O & 0 & O & 0 & $\mathrm{O}$ & - & 0 & 0 & 0 & 0 & 0 \\
\hline 10) Skilled suppliers & $\mathrm{O}$ & 0 & ○ & $\mathrm{O}$ & O & O & 0 & 0 & 0 & 0 & 0 \\
\hline
\end{tabular}

1) Skilled employees include all attempts to provide the appropriate know-how to the employees in order to fulfill their tasks highly motivated [2], [18]. KPIs to measure the skills of employees differ in content and notation. Often it is not clear how to quantify the indicators [22], [27], and [28].

2) Skilled organization refers to the potential of the organization to respond to structural changes and to changes regarding the task on short notice. Furthermore, internal obstacles should be reduced and know-how of past projects needs to be managed [2], [16]. The proposed indicators to evaluate the organization vary widely. Furthermore, they are often not well defined and difficult to quantify in practice [22], [23], [26], and [28].

3) Skilled supplier describes the effort to establish an optimal and trustful cooperation with external parties which contribute to the development (e.g. external supplier development) [2], [9]. Just a few KPI-Sets include KPIs to measure the abilities of the suppliers and the cooperation [26]-[28], and [17].

The analysis shows that yet no holistic KPI-Set covers all previously identified targets. Especially in the category capabilities the number of authors that are presenting KPIs is low. Additionally, many authors suggest to measure indicators like "innovation", without giving any details how this quite abstract parameter may be measured.

\section{APPROACH FOR AN HOLISTIC KPI-SET}

The analysis shows that many authors already describe a variety of KPIs for product development. Actually, there is no holistic KPI-Set which covers all identified targets. To develop a holistic KPI-Set enterprises have to regard some criteria. [16] First, it is important that the target groups in the KPI-Set are balanced. This means that the enterprise measures KPIs of each target group. Due to this, it should be avoid that enterprises focus their optimizations on just one target group. Only the optimization of all target groups has a sustainable impact for an enterprise. Furthermore, the enterprise has to choose KPIs aligned with the mentioned rules for creating performance indicators. To give an advice for the identified deficits of existing KPI-Sets, some KPIs to measure the targets of the target group capabilities are described.

As shown in the analysis, KPIs for skilled supplier barely exist. Reasonable KPIs to measure the benefit of a supplier could be summarized in a specific supplier assessment. A specific assessment of suppliers, which regards the context of development, is useful. E.g. the number of changes, compliance to deadlines, cooperation in workshops, participation on concept competitions, willingness for personnel exchanges and for conjoint project teams, should be considered.

Another deficit of the analysed KPI-Sets is the KPIs regarding skilled employees. To identify the right employee for a task, a competence index could support the choice. Soft skills like ability of teamwork can be only measured with a high subjectivity. The competence index shows the degree of congruency between competence and requirements.

With KPIs for each target the product development will have a balanced performance measurement system, which will lead to a higher overall performance.

\section{CONCLUSION}

In order to stay competitive, enterprises are forced to minimize waste in all processes and focus on value creation. The implementation of lean in development is an approach to focus on these aspects. However, a challenge within the implementation is to show that the lean concept pays off and also to control the roll-out. Because the processes in development differ in many aspects from the production process, specific KPI-Sets in development are needed.

An in-deep analysis showed that many KPI-Sets that measure the targets of development exist. Some having profound descriptions of several KPIs, but no KPI-Set regard all relevant target groups like effectiveness, efficiency, and capabilities. Especially the measurement of KPIs lacks in the target category capabilities. Also the analysis offers that it is 
difficult to measure the innovation in product development. For this the article gives examples for KPIs in these fields. Moreover a general set of KPIs was designed with the goal to evaluate the development process in a holistic and balanced way.

Based on the targets and a few examples for KPIs, enterprises are able to convey it to their own conditions to design an enterprise-specific KPI-Set. The benefit for enterprises is that they can design an individual KPI-Set to measure the current state in order to improve the processes of development.

\section{REFERENCES}

[1] VDI 2870, Lean production systems, original citation: Ganzheitliche Produktionssysteme, Germany: Beuth, 2010.

[2] J. M. Morgan and J. K. Liker, The toyota product development system, Productivity Press, New York, USA 2006.

[3] U. Dombrowski and T. Zahn, "Design of a lean development framework," in Proc. 2011 IEEM, Singapore, 2011, pp. 1917-1921.

[4] J. Hoppmann, "The lean innovation roadmap," Diploma Thesis, Institute of Automotive Management and Industrial Production, Technical University of Braunschweig, June 2009.

[5] J. Hentze, P. Brose, and A. Kammel, Unternehmungsplanung: Eine Einführung, 2nd. ed., Stuttgart, Bern, Wien, 1993.

[6] H. P. Wiendahl, Betriebsorganisation für Ingenieure, 4th ed., Hanser, München 1997.

[7] T. Reichmann, Controlling mit Kennzahlen und Managementberichten, 5. ed., München, 1997.

[8] U. Dombrowski and T. Zahn, "Wege zur effizienten Einführung von Lean Prinzipien in der Forschung und Entwicklung," presented at the Conference Lean Development, Cologne, Germany. February, 25-26, 2010.

[9] A. C. Ward, Lean Product and Process Development, Cambridge, MA, USA: The Lean Enterprise Institute, 2007.

[10] F. Nehuis, K. Schmidtchen, C. Stechert, S. Schulze, T. Vietor, and U. Dombrowski, "Methodology for the objectification of decisions in the Product Development," in Proc. the ICMIE, Singapore, February, 26-28, 2011.

[11] G. Schuh, M. Lenders, J. Arnoscht, and S. Rudolf, Effizienter innovieren mit Produktbaukästen, Werkzeugmaschinenlabor WZL, Aachen, Germany:, 2010.

[12] A. Feggeler and U. Husmann, Erfolgsfaktor Kennzahlen, Köln, Germany, 2000, Bachem.

[13] S. Globerson, "Issues in developing a performance criteria system for an organization," Int. J. Production Research, vol. 23, no. 4, pp. 639-646, 1985.

[14] B. Maskell, "Performance measures of world class manufacturing," in Management Accounting, May 1989, pp. 32-33.

[15] A. Neely, M. Gregory, and K. Platts, "Performance measurement system design: A literature review and research agenda," Int. J. Operations and Production Management, vol. 15, no. 4, pp. 80-116, 2005.

[16] V. Mahidhar, "Designing the lean enterprise performance measurement system," M.S. thesis. Dept. Eng. Sys., MIT, MA, USA, 2005.

[17] H. A. Zheng, J. J. Chanaron, J. X. You, and X. L. Chen, "Designing a key performance indicator system for technological innovation audit at firm's level: A framework and an empirical study," in Proc. IEEM, pp. $1-5,2009$.

[18] C. Sehested and H. Sonnenberg, Lean Innovation - A Fast Path from Knowledge to Value, Heidelberg, Germany, 2011.

[19] J. Sandström and J. Toivanen, "The problem of managing product development engineers: Can the balanced scorecard be an answer?" Int. J. Production Economics, vol. 78, pp.79-90, 2002.
[20] A. Griffin and A. L. Page, "An interim report in measuring product development success and failure," J. Prod. Innov. Manag., vol.10, no. 4, pp. 291-308, 1993.

[21] M. V. Tatikonda, "Product development performance measurement," The Handbook of New Product Development, Oxford, United Kingdom: Elsevier, pp. 199-215, 2007.

[22] Z. Bai, P. Zhang, F. Liu, and R. Tan, "Product development performance measures in manufacturing firm," in Proc. the IEEE Industrial Engineering and Engineering Management, Singapore, December 2-4, 2007

[23] A. Jedlitschka, "Key performance indikatoren der produktentwicklung," IESE-Report 085.05/D, Kaiserslautern, Deutschland, 2005.

[24] Quality management systems - fundamentals and vocabulary, EN ISO 9000:2005.

[25] K. S. Pawar and H. Driva, "Performance measurement for product design and development in a manufacturing environment," Int. $J$. Production Economics, vol. 60-61, pp. 61-68, 1999.

[26] Y. S. Hyun, "The Road to the self-reliance new Product Development of Hyundai Motor Company," Int. Motor Vehicle Program, 1995.

[27] B. Kim and H. Oh, "An effective R\&D performance measurement system: Survey of Korean R\&D researchers," Omega the Int. J. o. Mgt. Sci, vol. 30, pp. 19-31, 2002.

[28] R. K. Lenz and D. S. Cochran, "The application of axiomatic design to the design of the product development organization," in Proc. of ICAD, Cambridge, MA, USA, June 21-23, 2000, pp. 18-25.

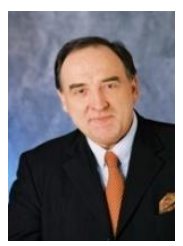

Uwe Dombrowski is the executive director of the Institute for Advanced Industrial Management at the Technische Universität Braunschweig in Germany. His fields of research include factory planning, production planning and control, logistics, management systems and enterprise organisation, ergonomics and human factors. Prior to his work at the Technische Universität Braunschweig professor Dombrowski held management positions such as head of department and managing director at Philips Medical Systems (Philips Medizin Systeme GmbH, Hamburg/Germany) and Porsche (Dr.-Ing. h. c. F. Porsche AG, Stuttgart/Germany). Professor Dombrowski is a member of several professional societies like Verband Deutscher Ingenieure e.V. (VDI), REFA and Deutsche MTM Vereinigung e.V. Professor Dombrowski of the European Academy for Industrial Management (AIM). In 2011 he was elected as vice-president of AIM. He is chairman of the board for the german conference on After Sales Service, Lean Production Systems and Factory Planning.

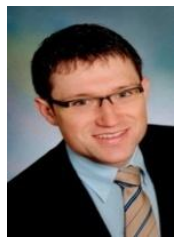

Kai Schmidtchen was born in 1984 in Datteln, Germany In 2003 he started his studies of industrial engineering and management at the Technische Universität Dortmund. Here he has focused on production management. After his diploma thesis in 2009 he worked as a research associate at the institute for Advanced Industrial Management. His fields of research include management systems and enterprise organization. Thereby he specialized on issues around lean development.

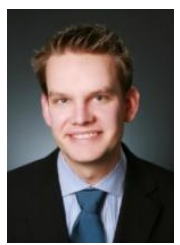

David Ebentreich was born in 1983 in Wilhelmshaven, Germany. In 2004 he started his studies of industria engineering and management at the Technische Universität Braunschweig. Here he has focused on production and systems engineering. After his diploma thesis he worked as a research associate at the institute for Advanced Industrial Management. His fields of research include management systems and enterprise organization. Thereby he specialized on issues around lean development and lean hospital. 